\title{
Digestion characteristics and kinetic analysis of bio- molecules in a simulated human intestinal system
}

\author{
Ae-Jin Choi ${ }^{1}$, Natalee Buisson ${ }^{2}$ and Chong-Tai Kim ${ }^{3 *}$ \\ ${ }^{1}$ Postharvest Research Team, National Institute of Horiculture and Herbal Science, RDA, Wanju-gun, Republic of Korea \\ ${ }^{2}$ Department of Chemical and Biomolecular Engineering, Tulane University, New Orleans, USA \\ ${ }^{3}$ Bioprocess Research Group, Korea Food Research Institute, Seongnam-si, Gyeonggi-do, Republic of Korea
}

\begin{abstract}
We designed and assembled a simulated human intestinal system (SHIS) consisting of a stomach and a small intestine. Each reactor vessel has several ports such as the input and output of medium, a sampler of liquid phase, a pH electrode, a pH control (acid and base), and a thermometer. The SHIS was kept at body temperature $\left(37^{\circ} \mathrm{C}\right)$ by pumping water into the space between the jacket and the inside walls. The stomach chamber was initially filled with gas fluids and then digested for 2 hr. After the stomach digestion, the residuals was delivered from stomach chamber into the small intestine chamber by secreting intestinal fluid for 4 hr, followed by secretion of $0.3 \mathrm{M} \mathrm{NaHCO}_{3}, 0.1 \mathrm{M} \mathrm{NaHCO}, 4 \%$ bile salt, and $2 \%$ bile salt for $1,3,0.5$, and 3.5 hrs, respectively. In order to prepare the alginate/chitosan capsule as a delivery system for bioactive agents, the microencapsulation system was assembled with a control unit, a electrical, a pneumatic systems, and a reaction vessel. After digestion of alginate capsules, the content of total sugar was $7.47 \%$ and $60.82 \%$ in the stomach and small intestine (simulated human intestinal system, SHIS), respectively. However, in case of alginate/chitosan capsule and alginate/chitosan capsule coated with polyacryl emulsion (alginate/chitosan-PAE), the total sugar content were 3.12 and $4.62 \%$ in the stomach model and 43.46 and $42.09 \%$ in the small intestine model, respectively. There were no difference on the degree of digestion in the alginate capsule and alginate/polyethylene glycol (alginate/PEG) capsule prepared with $0.1-0.3 \%$ of PEG in the stomach model. As a result, the alginate matrix remained in a shrunken state due to conversion of sodium alginate into insoluble alginic acid, which acted as a barrier to chitosan microparticles. And it was effective for digesting by intestinal fluid and releasing of the sugar.
\end{abstract}

\section{Introduction}

Recently a dynamic, computer-controlled model has been developed that allows the simulation of successive in vivo condition in the stomach and small intestine such as the kinetics of $\mathrm{pH}$, bile salt concentration, and transit of the chime [1-3]. Despite these advances in physiological modeling and simulation of drug adsorption from the gastrointestinal tract, the fundamental process, which is the small intestinal transit flow, has not been characterized [4-6].

The benefits of encapsulating and releasing a therapeutic agent from the polymer matrix include protecting the sustained release of the encapsulated substances. The use of microcapsules and microspheres is very promising because of their particle size, enabling repetitive administrations as a therapeutic bolus by either an injection or an oral route. Biocompatible and biodegradable materials that include natural polymers (chitin, chitosan, alginate, xanthane, etc.) and synthetic biodegradable polymers [poly(lactic-co-glycolic acid), poly(lactic-coamide), etc.] have been thoroughly investigated for this purpose $[7,8]$.

Among them, alginate hydrogels which ionically cross-links in the presence of multivalent cations, have been extensively investigated due to their biocompatibility $[9,10]$. In addition, polycationic chitosan has been known to enhance drug absorption by modulating the tight junctions of the gastrointestinal epithelial barrier [11-13]. Also, PEG is one of the most frequently used water-soluble polymers for biomedical applications because of its high water solubility and chain flexibility as a synthetic non-degradable polymer [14].

Polymer-based delivery systems that trap molecules of interest within networks have been developed extensively for the biomedical and pharmaceutical fields. So far there are no delivery systems for foods which are designed to enhance the efficiency and stability of bioactive agents [15].

In this study, we prepared alginate/chitosan microcapsules encapsulating bioactive ingredients by encapsulators and investigated the effects of polymer type and co-polymer concentration on the efficiency yield under optimum conditions of encapsulation system such as polymer concentration, feeding speed, frequency, and nozzle size. The characteristics of digestion kinetics and bioavailability of catechin-loaded macrocapsule, starch, and soyprotein isolate were analyzed with the simulated human intestinal system (SHIS). The operating condition of SHIS was optimized with feeding fluid, feeding rate, and reaction time.

\section{Materials and methods}

\section{Manufacture of microcapsules}

Preparation of microcapsule ingredient: Alginate (from Macrocystis pyrifera, medium viscosity, A-7033, Sigma, MO, USA) was prepared $1.5 \%(\mathrm{w} / \mathrm{v})$ solution then boiled for $30 \mathrm{~min}$ at $100^{\circ} \mathrm{C}$ to

Correspondence to: Chong-Tai Kim, Bioprocess Research Group, Korea Food Research Institute, Seongnam-si, Gyeonggi-do, 463-746, Republic of Korea, Tel: +82-31-780-9138; Fax:+82-31-780-9257; E-mail: ctkim@kfri.re.kr

Key words: alginate microcapsule, kinetic analysis, microencapsulation,natural polymer, transport characteristics

Received: May 22, 2015; Accepted: June 18, 2015; Published: June 22, 2015 
dissolve completely. $200 \mathrm{~g}$ of chitosan (Deacetylation 93, Mw 330,000) was dispersed in mixture solution of $20 \mathrm{~L}$ deionized water adjusted at $\mathrm{pH} 5.6$ and $227 \mathrm{mLHCl}$ with an agitator for $30 \mathrm{~min}$ at $25^{\circ} \mathrm{C}$. This was then dissolved for $3 \mathrm{hr}$ and purified with ultra filtration equipment. Manufactured chitosan was prepared with $0.3 \%(\mathrm{w} / \mathrm{v})$ solution. Polyethylene glycol was purchased from Fluka Chemie AG (Mw 20,000, 81300, Buchs, Germany). Polyacryl emulsion (Kollicoat SR 3D, BAFS, Ludwigshafen, Germany) was used as coating material. (+)-Catechin hydrate was purchased from Sigma (minimum 98\%, C1251, Sigma, MO, USA).

Operating condition of encapsulation system: Monodispersed alginate microcapsules were prepared using an encapsulator (IE-50R, Inotech Encapsulation AG, Dottikon, Switzerland) based on laminar jet break-up induced by applying a sinusoidal frequency with defined amplitude to the nozzle. The system was composed of a control unit, an electrical system, a pneumatic systems, and a reaction vessel (Figure 1). $150 \mu \mathrm{m}$ diameter nozzles were used connected via a steel or PTFE membrane to a vibrating device. A precision syringe pump is used for extrusion volumes of up to $50 \mathrm{~mL}$ of alginate. The optimal condition of operation determined based on process parameters such as feed rate of alginate, vibrational frequency for droplet formation, and electrostatic charge control [7].

Manufacture of biopolymer microcapsules: For the production of $<50 \mathrm{~mL}$ of microcapsules, $1.5 \%$ alginate solution was extruded at the rate of $2.75 \mathrm{~g} / \mathrm{min}$ into $100 \mathrm{mM} \mathrm{CaCal}(500 \mathrm{~mL}), 100 \mathrm{mM} \mathrm{CaCl}_{2}$ containing $0.3 \%$ chitosan, and $100 \mathrm{mM} \mathrm{CaCl}_{2}$ containing $0.05,0.1,0.2$, and $0.3 \%$ polyethylene glycol(PEG) dissolved in $0.1 \mathrm{M}$ Tris- $\mathrm{HCl}$ buffer

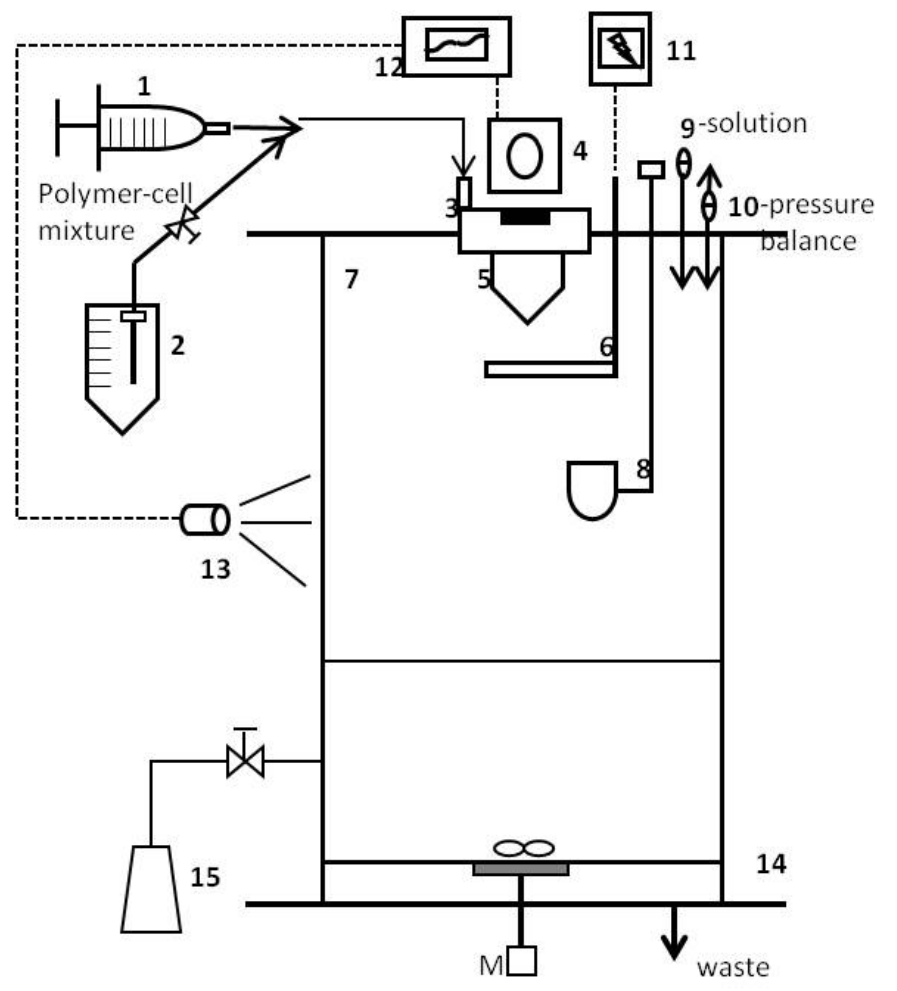

Figure 1. Schematic diagram of monodispersion microencapsulation.

1: Syringe, 2: Product delivery bottle, 3: Pulsation chamber, 4: Variation system, 5: Nozzle, 6: Electrode, 7: Reaction vessel, 8: Bypass-cup, 9: Liquid filter, 10: Air filter, 11: Electrostatic charge generator, 12: Frequency generator, 13: Stroboscope, 14: Filtration grid, 15: Bead collection flask, M: Magnetic stirrer, P: Pressure control system, S: Syringe pump.
(pH 5.0). Continually agitate mixture using magnetic stirrer to avoid coalescence of microcapsules during polymerization.

The alginate concentration, which strongly affects the fluid viscosity, was adjusted in such a way that bead integrity was manufactured by contact with the stirred $\mathrm{CaCl}_{2}$ solution. If the concentration was too low, the formed droplets collapse on contact with the surface of $\mathrm{CaCl}_{2}$ solution to form nonspherical particles. A good compromise was achieved with alginate concentrations between 1 and 2.5\%, depending on the mean molecular weight of the alginate.

After standing for $15 \mathrm{~min}$ at room temperature, the formed capsules were washed with deionized water three times. Then the capsules were kept for $1 \mathrm{hr}$ at room temperature to remove surface water of microcapsules and stored at $4^{\circ} \mathrm{C}$ for a biochemical assay. Then, the washed microcapsules were treated in the polyacryl emulsion (PAE) with 10 times volume of microcapsule weight for $30 \mathrm{~min}$, as coating material.

Manufacture of catechin microcapsules: The catechin microcapsules were prepared using an encapsulator (IE-50R, Inotech Encapsulation AG, Dottikon, Switzerland) based on two nozzles and air pressure. The alginate solution ( $1.5 \%$, medium viscosity) was extruded through the coating nozzle $(500 \mu \mathrm{m})$ at arate of $6.5 \mathrm{~g} / \mathrm{min}$ and with an air pressure of 0.6 bar into $100 \mathrm{mM} \mathrm{CaCal}{ }_{2}(500 \mathrm{~mL})$. At same time, catechin solution $(0.5 \%)$ was extruded through the core nozzle (150 $\mu \mathrm{m})$ at arate of $1.9 \mathrm{~g} / \mathrm{min}$ using a piston pump into $100 \mathrm{mM} \mathrm{CaCal}_{2}$.

Catechin microcapsules were agitated continuously with a magnetic stirrer to avoid coalescence of microcapsules during polymerization. After standing for $15 \mathrm{~min}$ at room temperature, the formed capsules were washed with deionized water three times. Then the capsules were kept for $1 \mathrm{~h}$ at room temperature to remove surface water of microcapsules and stored at $4^{\circ} \mathrm{C}$ for a biochemical assay.

Starch and soy protein isolate for digestion in the SHIS: The release of starch and soy protein isolate used as physiological material in order to investigate the digestion characteristics and kinetic analysis of nutrient bio-molecules in the SHIS. Starch slurry and soy protein isolate solution was prepared at 5 and $2.5 \%$, respectively.

\section{Experimental design of simulate human intestinal system}

\section{Preparation of digestive reagent}

\section{1) Gastric fluid}

Pepsin $0.1 \mathrm{~g}$ (from Porcine stomach mucosa, P-7125, Sigma, MO, USA), Mucin (from porcine stomach, M2378, Type II, Sigma, MO, USA), and $\mathrm{NaCl} 8.5 \mathrm{~g}$ dissolved in $1 \mathrm{~L}$ deionised water and adjusted $\mathrm{pH}$ 2.0 with $1 \mathrm{~N} \mathrm{HCl}$.

\section{2) Small intestine fluid}

Trypsin $0.1 \mathrm{~g}$ (from porcine pancreas, T-4799, Sigma, MO, USA) and pancreatin $3.5 \mathrm{~g}$ (P-8096, Sigma, MO, USA) dissolved in $1 \mathrm{~L}$ deionised water.

\section{3) Bile acid fluid}

Bile bovine (B3883, Sigma, MO, USA) prepared with a concentration of $4 \%$ in deionised water. The concentrations of bile salts in the experiments simulating the physiological conditions were the same as those described by Minekus et al. [3].

\section{Design and assembly of the SHIS}

The simulate human intestinal system (SHIS) was prepared 
by modified method of Ainsely et al. [8], Blanquet et al. [16]. It was displayed on the Figures 2 and 3. The model was consisted of two compartments simulating the stomach and small intestine, which are connected by computer-controlled pumps and formed by jacketed glass beakers (Dosung scientific, Seoul, Korea). A cover was designed to accommodate a $\mathrm{pH}$ electrode $(\mathrm{pH} 502 / \mathrm{mV} 602$ Series, Hanna instrument, RI, USA), a temperature probe, and entry ports for gastric fluid (GF) and $0.1 \mathrm{M} \mathrm{HCl}$ delivery into the stomach reactor. For the small intestine reactor, there were four entry ports for digested products of the stomach, the small intestine fluid (IF), the bile acid fluid (BF), and $0.3 \mathrm{M} \mathrm{NaHCO}_{3}$. A magnetic stirrer bar was placed inside each vessel, and agitation was controlled via a magnetic stirrer plate (Corning, MA, USA). The temperature inside the reactors was controlled by circulating water $37^{\circ} \mathrm{C}$ through the jacketed beakers. Secretions of GF into the stomach reactor and of IF and BF into small intestinal reactor are regulated using computer controlled peristaltic pumps (SMP-21, Eyela, Tokyo, Japan).

The optimal condition of reaction was shown in the Table 1 , and the $\mathrm{pH}$ value of the stomach reactor was controlled at $\mathrm{pH} 2.0$ with $1 \mathrm{M}$ $\mathrm{HCl}$ (highest speed) for $2 \mathrm{hr}$ to reproduce physiological conditions. 0.3 $\mathrm{M} \mathrm{NaHCO}_{3}$ (highest speed) was added to the small intestine reactor to

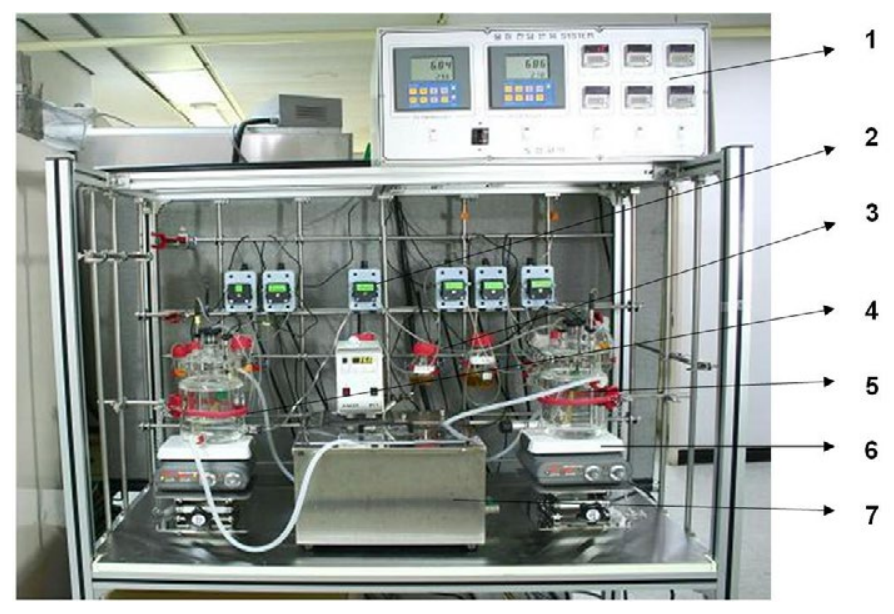

Figure 2. Apparatus of the simulated human intestinal system (SHIS).

1: Control system ( $\mathrm{pH} \&$ pump), 2: Peristaltic pump, 3: Gastric \& intestinal fluid-HCl, bile salt, 4: Stomach vessel, 5: Small intestine vessel, 6: Magnetic stirrer, 7: Temperature controller.

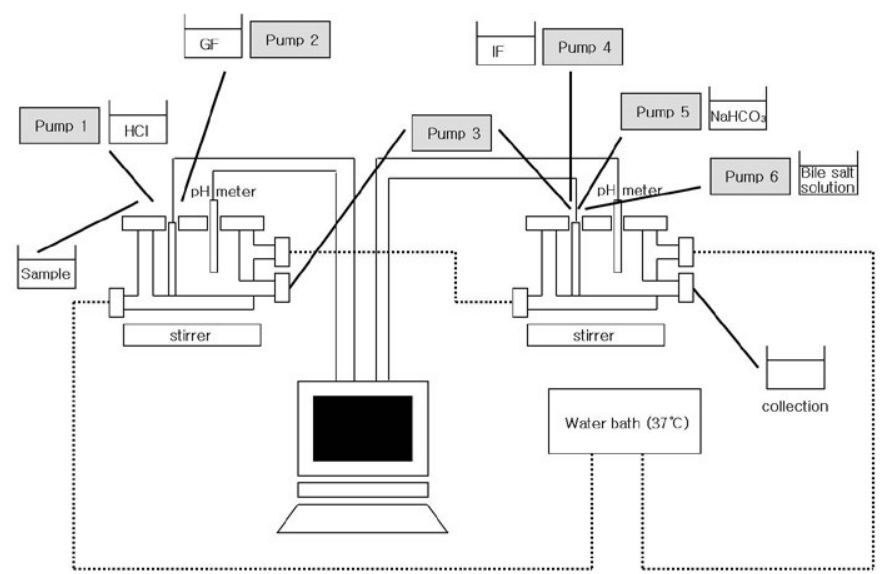

Figure 3. Schematic diagram of the simulated human intestinal system (SHIS). GF: Gastric fluid, IF: Intestinal fluid
Table 1. Feed composition, working volume, residence time and feed rate in the simulated human intestinal system.

\begin{tabular}{|c|c|c|c|c|c|}
\hline Vessel & Pump & Feeding fluid & $\begin{array}{c}\text { Working Volume } \\
(\mathrm{mL})\end{array}$ & $\begin{array}{c}\text { Time } \\
\text { (hr) }\end{array}$ & $\begin{array}{l}\text { Feed rate } \\
(\mathrm{mL} / \mathrm{min})\end{array}$ \\
\hline \multirow{2}{*}{$\begin{array}{c}\text { I } \\
\text { (Stomach) }\end{array}$} & 1 & $0.1 \mathrm{M} \mathrm{HCl}$ & & & $\mathrm{pH}$ maintain \\
\hline & 2 & ${ }^{*} \mathrm{GF}$ & 39.6 & 2 & 0.33 \\
\hline \multirow{3}{*}{$\begin{array}{c}\text { II } \\
\text { (Small intestine) }\end{array}$} & 3 & 'IF & 79.2 & 4 & 0.33 \\
\hline & 4 & $0.3 \mathrm{M} \mathrm{NaHCO}_{3}$ & & & $\mathrm{pH}$ maintain \\
\hline & 5 & $4 \%$ bile salt & 67.5 & 2 & 0.28 \\
\hline
\end{tabular}

*GF :Gastric fluid

IF: Intestinal fluid

maintain the $\mathrm{pH}$ at 6.8 for $4 \mathrm{hr}$. The secretion of GF, IF and BF was set to $0.33 \mathrm{~mL} \mathrm{~min}^{-1}, 0.33 \mathrm{~mL} \mathrm{~min}^{-1}$, and $0.28 \mathrm{~mL} \mathrm{~min}^{-1}$, respectively.

Microcapsules (20 g) for SHIS reaction were prepared with $100 \mathrm{~mL}$ of deionized water in the stomach reactor. During reaction in the SHIS, $10 \mathrm{~mL}$ of digested products were collected after 1,2,3,4, and $6 \mathrm{hrs}$ from the stomach and small intestine reactor. The total volume of digested products was measured at each sampling time, and the concentration of total carbohydrate (TCH) was determined in each sample.

\section{Analytical methods}

Kinetic analysis of microcapsules: The concentration of TCH was determined in samples of digested product with phenol-sulfuric acid method. TCH concentrations was also determined colorimetrically with a spectrometer at $490 \mathrm{~nm}$ (V550, Jasco, Tokyo, Japan). The TCH of $\mathrm{GF}, \mathrm{IF}$, and BF was exempted from digested products due to calculated digestion kinetics of microcapsule by the SHIS reaction.

\section{(1) Stomach reactor}

\section{Residual TCH $(\mu \mathrm{g})=\mathrm{C}-(\mathrm{A}-\mathrm{G})$}

Where $\mathrm{A}$ is $\mathrm{TCH}$ of digested product in the stomach reactor $(\mu \mathrm{g})$, $\mathrm{G}$ is $\mathrm{TCH}$ of $\mathrm{GF}(\mu \mathrm{g})$, and $\mathrm{C}$ is $\mathrm{TCH}$ of microcapsule in the digestion experiment $(\mu \mathrm{g})$. Residual $\mathrm{TCH}(\mu \mathrm{g})$ was expressed with the $\ln (\mathrm{C})$ by logarithmic function

\section{(2) Small intestine reactor}

$$
\text { Residued } \mathrm{TCH}(\mu \mathrm{g})=\mathrm{C}-(\mathrm{A}-\mathrm{G}-\mathrm{I}-\mathrm{B})
$$

Where $\mathrm{A}$ is $\mathrm{TCH}$ of digested product in small intestine reactor $(\mu \mathrm{g})$, $\mathrm{G}$ is $\mathrm{TCH}$ of $\mathrm{GF}(\mu \mathrm{g})$, I is TCH of $\mathrm{IF}(\mu \mathrm{g}), \mathrm{B}$ is $\mathrm{TCH}$ of $\mathrm{BF}(\mu \mathrm{g})$, and $\mathrm{C}$ is $\mathrm{TCH}$ of microcapsule in the digestion experiment $(\mu \mathrm{g})$. Residual $\mathrm{TCH}(\mu \mathrm{g})$ was expressed with the $\ln (\mathrm{C})$ by logarithmic function

Kinetic analysis of catechin microcapsules: Kinetics analyses of catechin microcapsules by the SHIS were measured with total polyphenol contents, which were described by the modified FolinCiocalteu method [17]. Briefly, $1 \mathrm{~mL}$ of $1 \mathrm{~N}$ Folin-Ciocalteu reagent was added to a $1 \mathrm{ml}$ sample, and this mixture was allowed to stand for $5 \mathrm{~min}$ before the addition of $2 \mathrm{~mL}$ of $20 \% \mathrm{Na}_{2} \mathrm{CO}_{3}$. The solution was then allowed to stand for 10 more minutes before reading were taken at 730 $\mathrm{nm}$ in a Jasco V550 spectrophotometer (V550, Jasco, Tokyo, Japan). Total polyphenol content was expressed as milligram equivalents to the standard ((+)-catechin hydrate) used per milliliter of aqueous solution. The calculation method was equaled to the kinetic analysis of TCH.

Kinetic analysis of starch and SPI: The kinetic analysis of starch and SPI was with the phenol-sulfuric acid method and the Lowry method [18], respectively. 


\section{Results and discussion}

\section{Assembly of the simulated human intestinal reactor and performance test}

Input reactant of in the SHIS: The secretion of GF, IF and BA was set to $0.33 \mathrm{~mL} \mathrm{~min}^{-1}, 0.33 \mathrm{~mL} \mathrm{~min}^{-1}$, and $0.28 \mathrm{~mL} \mathrm{~min} \mathrm{~m}^{-1}$, respectively. The GF, IF, and BA were collected for volume measurements after $0.5,1,2,3,4$, and 6 hrs. Practically, the total volumes of secretion in proportion to SHIS reaction time are shown in Table 2 and that were somewhat lower than working volumes of setting feed rate however, both of volumes were not showed great difference. At the initial stage, the $1 \mathrm{M} \mathrm{HCl}$ was added $5 \mathrm{~mL}$ to the stomach reactor to maintain the $\mathrm{pH}$ at 2.0 and $0.3 \mathrm{M} \mathrm{NaHCO}_{3}$ was added $20 \mathrm{~mL}$ to the small intestine reactor to maintain the $\mathrm{pH}$ at 6.8 .

Marteau et al. [1] also reported similarly that the secretion into the gastric compartment comprised the electrolyte solution with pepsinogen at a flow rate of $0.25 \mathrm{mLmin}^{-1}$ and $1 \mathrm{M} \mathrm{HCl}$ at a flow rate of $0.25 \mathrm{mLmin}^{-1}$ to maintain $\mathrm{pH}$. Deodenal secretion contained the electrolyte solution at a flow rate of $0.25 \mathrm{mLmin}^{-1}, 7 \%$ pancreatine in a $0.3 \mathrm{M}$ of $\mathrm{NaHCO}_{3}$ at a flow rate of $0.25 \mathrm{mLmin}^{-1}$, and bile at a concentration differing among the experiments at a flow rate 0.5 $\mathrm{mLmin}^{-1}$.

\section{Total sugar of the reactant after SHIS reaction}

The concentration of $\mathrm{TCH}$ was determined in each fluid so that the practical released amounts of contents in the stomach and small intestine reactor were measured in proportion to SHIS reaction time. The TCH of gastric fluid, intestinal fluid, and $4 \%$ bile acid was shown in the Table 3 to be $264.79,1370.25$ and $458.99 \mu \mathrm{g} / \mathrm{mL}$, respectively.

\section{Preparation of microcapsule, efficiency yield and moisture content}

Drug loading and encapsulation efficiency are important parameters to evaluate the properties of microcapsules [19]. A preparative method by complex coacervation is based on polyionic complexation through electrostatic interactions between cationic and anionic polymers, resulting in the formulation of insoluble spherical capsules [20]. Table 4 shows

Table 2. Feeding volume of digestive solution and chemicals in simulated human intestinal system during digestion of $1.5 \%$ alginate microcapsules.

\begin{tabular}{|c|c|c|c|c|c|c|}
\hline \multicolumn{2}{|c|}{$\begin{array}{l}\text { Reaction time } \\
\text { (h) }\end{array}$} & $\begin{array}{c}\text { 0.1N-HCI } \\
(\mathrm{mL})\end{array}$ & $\begin{array}{l}{ }^{*} \mathbf{G F} \\
(\mathrm{mL})\end{array}$ & $\begin{array}{c}{ }^{\dagger} \mathbf{I F} \\
(\mathrm{mL})\end{array}$ & $\begin{array}{c}4 \% \text { ( } \mathrm{BA} \\
(\mathrm{mL})\end{array}$ & $\begin{array}{c}\text { 0.3M-NaHCO } \\
(\mathrm{mL})\end{array}$ \\
\hline \multirow{3}{*}{$\begin{array}{l}\text { Vessel I } \\
\text { (Stomach) }\end{array}$} & 0.5 & 5 & 9 & & & \\
\hline & 1 & & 18 & & & \\
\hline & 2 & & 36 & & & \\
\hline \multirow{3}{*}{$\begin{array}{c}\text { Vessel II } \\
\text { (Small intestine) }\end{array}$} & 3 & & & 17 & 15 & 20 \\
\hline & 4 & & & 34 & 30 & \\
\hline & 6 & & & 68 & 60 & \\
\hline
\end{tabular}

*GF :Gastric fluid

IF: Intestinal fluid

${ }^{\ddagger}$ BA: Bile acid

Table 3. Total carbohydrate of gastric fluid, intestinal fluid and $4 \%$ bile acid.

\begin{tabular}{|c|c|}
\hline & "TCH $(\mu \mathrm{g} / \mathrm{ml})$ \\
\hline Gastric fluid & $266.16 \pm 12.92$ \\
\hline Intestinal fluid & $1391.0 \pm 99.66$ \\
\hline $4 \%$ bile acid & $452.39 \pm 29.96$ \\
\hline
\end{tabular}

*TCH : Total carbohydrate
Table 4. Yield and moisture contents of microcapsules with alginate, chitosan and polyacryl emulsion.

\begin{tabular}{|l|c|c|}
\hline Microcapsules & Efficiency yield (\%) & Moisture (\%) \\
\hline${ }^{*} \mathrm{~A}$ & $37.58 \pm 0.11^{\mathrm{B}}$ & $95.67 \pm 0.02^{\mathrm{B}}$ \\
\hline${ }^{\circ} \mathrm{A} /$ Chito & $38.57 \pm 0.09^{\mathrm{A}}$ & $96.66 \pm 0.01^{\mathrm{A}}$ \\
\hline${ }^{\ddagger} \mathrm{A} /$ Chito-C & $26.39 \pm 0.02^{\mathrm{C}}$ & $93.25 \pm 0.03^{\mathrm{C}}$ \\
\hline F-value & $19445.2^{* * *}$ & $26831.3^{* * *}$ \\
\hline
\end{tabular}

$* \mathrm{~A}: 1.5 \%$ alginate microcapsules

${ }^{\dagger} \mathrm{A} /$ Chito: $1.5 \%$ alginate $/ 0.3 \%$ chitosan microcapsules

${ }^{\star} \mathrm{A} /$ Chito-C: $1.5 \%$ alginate $/ 0.3 \%$ chitosan microcapsules coated with polyacryl emulsion

Mean in the same column with the different letters (A-C) are significantly different at $\mathrm{p}<0.05$ by Duncan's multiple test

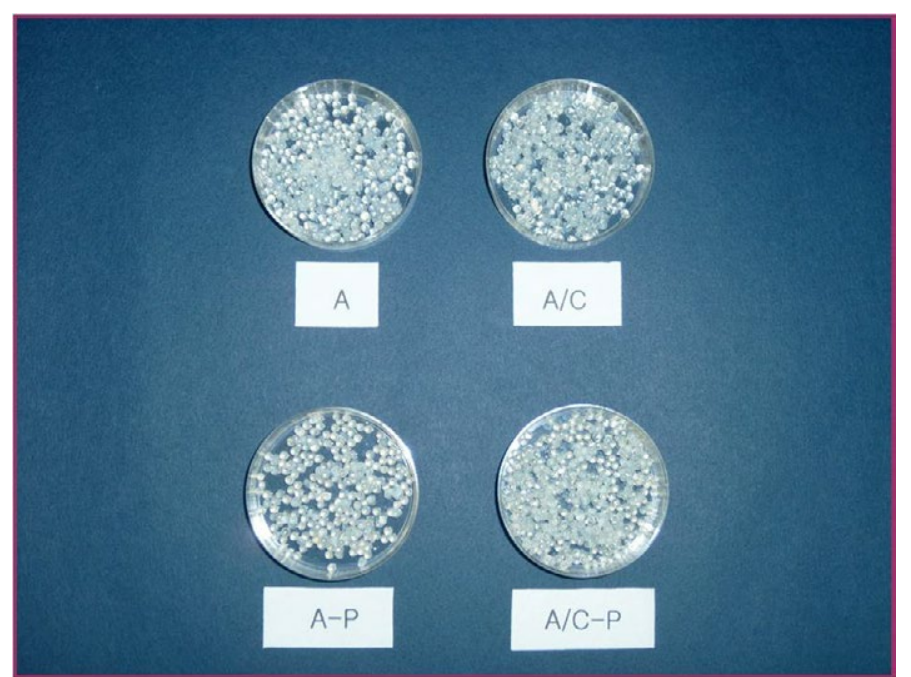

Figure 4. Photograph of alginate, alginate/chitosan and alginate/PEG microcapsules.

A: $1.5 \%$ alginate microcapsules, $\mathrm{A} / \mathrm{Chito}: 1.5 \%$ alginate $/ 0.3 \%$ chitosan microcapsules A-C: $1.5 \%$ alginate microcapsules coated with polyacryl emulsion, A/Chito-C: $1.5 \%$ alginate $/ 0.3 \%$ chitosan microcapsules coated with polyacryl emulsion.

the effects of capsulation materials on the efficiency yield of alginate, alginate/chitosan, alginate/PEG, and PAE coating. The alginate/ PEG capsules showed a higher value of efficiency yield than alginate and alginate/chitosan microcapsules, also, the efficiency yield of microcapsules increased upon increase of the PEG contents. There was no difference in the moisture contents of the capsules prepared with different capsulation material and coating material. The first product of microcapsules is shown in the Figure 4.

\section{Characterization of digestion property of microcapsule in the SHIS}

\section{Alginate and alginate/chitosan microcapsule}

The Figure 5 displays the release of alginate capsules, alginate/ chitosan capsules, and alginate/chitosan-PAE coated capsules as the three forms of the microcapsules during the SHIS reaction time. The rate of release was divided into a stomach phase (0-120 min) and a small intestine phase (120-360 min).

After digestion of alginate capsules, the content of total sugar was 7.47 and $60.82 \%$ in the stomach and small intestine phase, respectively. However, for alginate/chitosan capsules, the total sugar was $3.12 \%$ in the stomach phase and $43.46 \%$ in the small intestine phase. Alginate and alginate/chitosan microcapsule showed significant differences in the stomach and the small intestine phase. 


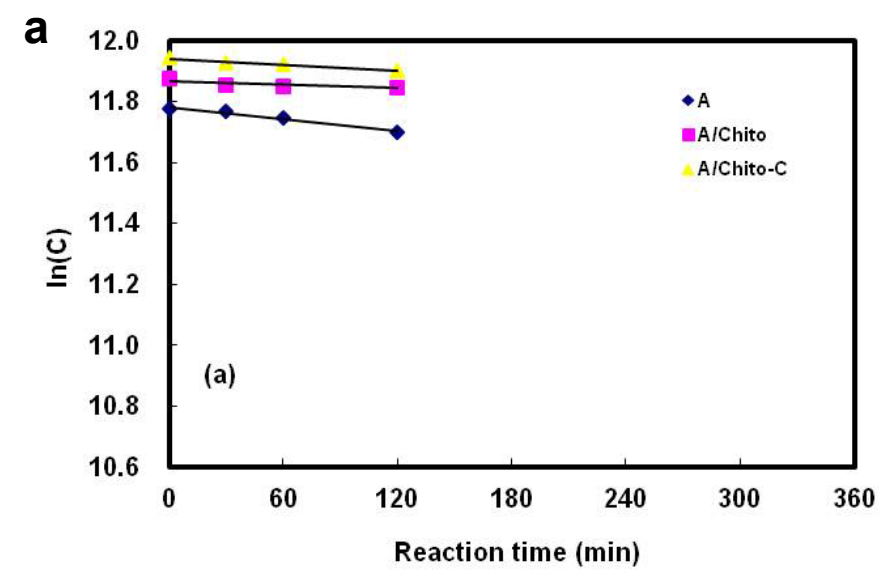

b

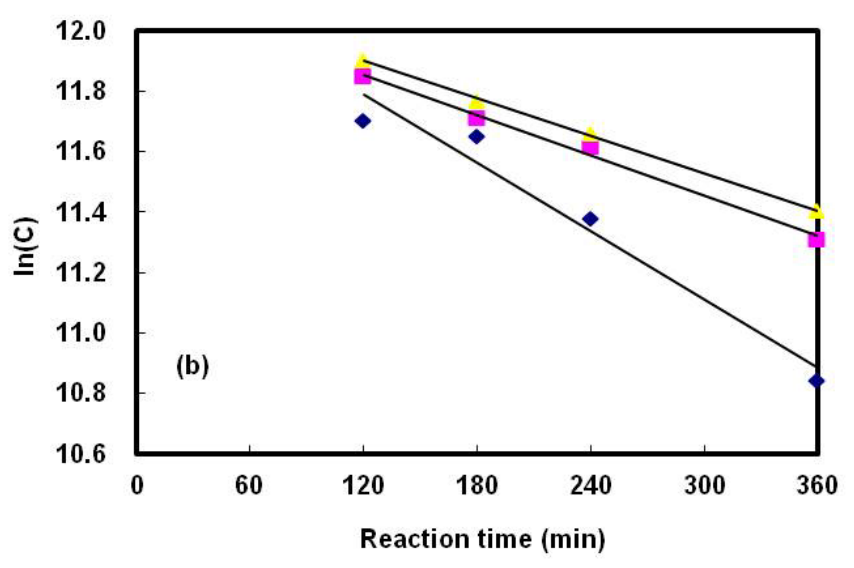

Figure 5. Digestion kinetics of alginate and alginate/chitosan microcapsules in the simulated human intestinal system.

(a) Stomach vessel, (b) Small intestine vessel, A: $1.5 \%$ alginate microcapsules, A/Chito: $1.5 \%$ alginate $/ 0.3 \%$ chitosan microcapsules, A/Chito-C: $1.5 \%$ alginate $/ 0.3 \%$ chitosan microcapsules coated with polyacryl emulsion.

Since alginate contains carboxylic acid groups on polyguluronate units, alginate microspheres exhibit negative surface charge, allowing them to be used as negatively charged templates for polyelectrolyte layer-by-layer assembly. The polyelectrolyte multilayer wall between alginate and natural polymers such as chitosan and synthetic polymer can provide a protective shell for encapsulated biomolecules, prolonging the life-span of alginate microspheres in a biological environment [9].

These results are consistent with those of Lim et al. [21], which suggested that the release of gentamicin from hyaluronic acid(HA) and hyaluronic acid/chitosan glutamate was longer than chitosan glutamate. Also, the combination of HA with chitosan may produce additional advantages by combining the mucoadhesive potential of HA with the penetration enhancing effect of chitosan.

However, in case of alginate/chitosan capsules and alginate/ chitosan-PAE coated capsules, the total sugar was 3.12 and $4.62 \%$ in the stomach phase and 43.46 and $42.09 \%$ in the small intestine phase. The addition of the PAE coating created infinitesimal differences in the digestion of microcapsules.

\section{Effect of PEG on formation of alginate microcapsule}

The release of alginate and alginate/PEG capsules prepared by the different contents of PEG during digestion in the SHIS is shown in Figure 6. The sugar release not complete from the microcapsules within the $6 \mathrm{hr}$ time-span. In addition, the release of sugar in the stomach phase was slower than the small intestine phase.

There were no differences on the degree of digestion in the alginate capsules and alginate/PEG capsules prepared with 0.1-0.3\% PEG in the stomach phase. However, the capsules prepared with $0.05 \%$ PEG showed a lower value than the others. And they did not show a significant difference indigestion rate in the stomach phase. Also in the small intestine phase, alginate capsules and alginate/PEG capsules containing $0.05,0.1,0.2$, and $0.3 \%$ PEG expressed consistent results. The total sugar content was $41,53,55$, and $47 \%$. The microcapsules prepared with the higher PEG contents showed an increased digestion. These results also might be due to the addition of PEG in the polyion complex between $\mathrm{Ca}^{+}$and alginate. Takayama et al. [22] investigated the effect of interpolymer complex formation between chitosan and hyaluronic acid in the tablets. The in vitro release and mucoadhesive properties of the complex of chitosan combined with HA in this dosage form were shown to be affected by a change in polymer mixing ratio, suggesting a possible interaction between chitosan and HA.
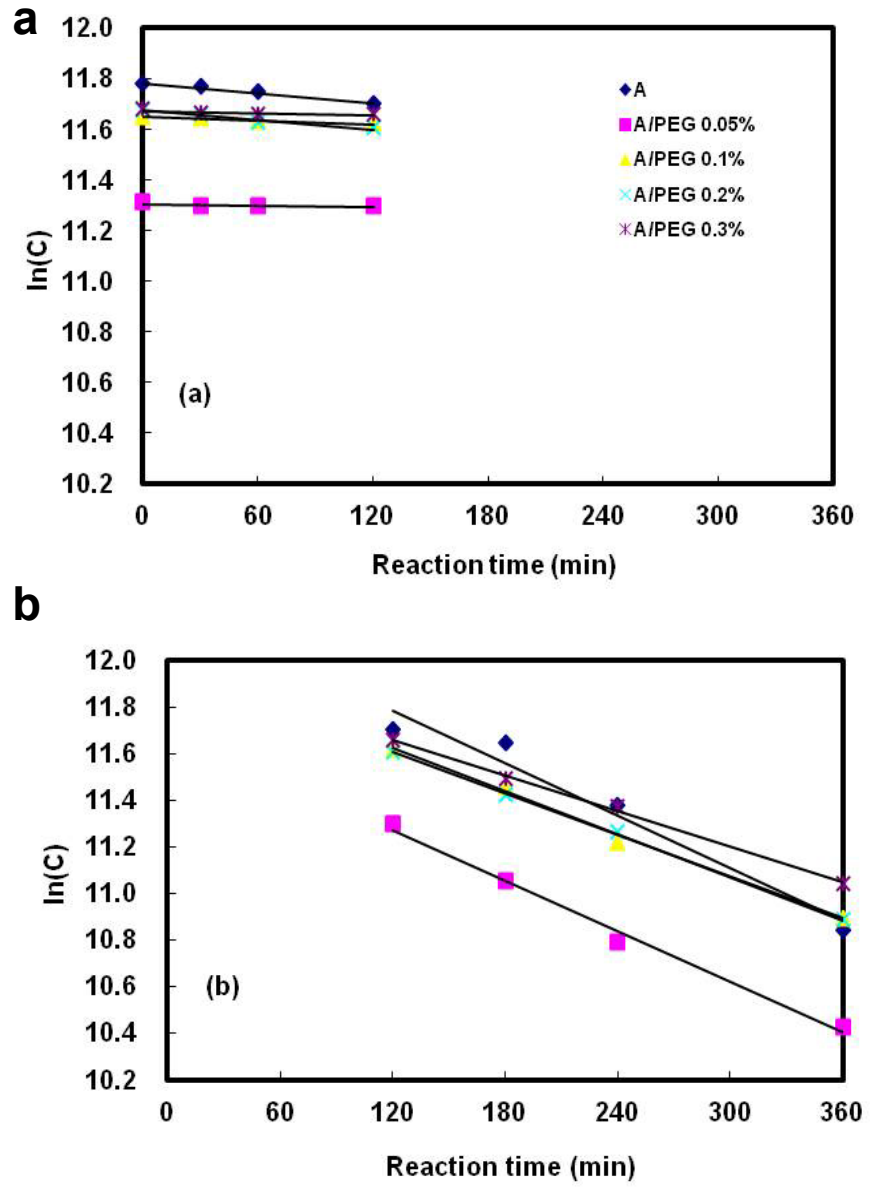

Figure 6. Effect of polyethylene glycol(PEG) concentration on the digestion kinetics of alginate/PEG microcapsules in the simulated human intestinal system.

(a) Stomach vessel, (b) Small intestine vessel, A: 1.5\% alginate microcapsules, A/PEG $0.05 \%(0.1 \%, 0.2 \%, 0.3 \%): 1.5 \%$ alginate $/ 0.05 \%(0.1 \%, 0.2 \%, 0.3 \%)$ polyethylene glycol microcapsules. 


\section{Effect of stabilization on formation of alginate and alginate/ PEG microcapsule}

The Figure 7 displays the release of alginate capsules and alginate/ PEG prepared by the different contents coated with PAE during SHIS reaction of the stomach and small intestine. The release of both alginate capsules not coated with PAE and alginate/PEG capsules coated with PAE expressed consistent results; however, the degree of digestion of the capsules coated with PAE was higher than the capsules not coated with PAE. These results presumed that the release of microcapsules in the small intestine phase was prolonged by the hydrophilic polyacryl emulsion.

Huiguang et al. [23] reported that calcium-cross-linked alginate hydrogel microspheres were fabricated by an emulsification technique and then used as negatively charged templates to form polyelectrolyte multilayer coatings. This spontaneous loading technique for encapsulating positively charged molecules in alginate-template polyelectrolyte microcapsules showed strong potential for biosensor and drug delivery application.

\section{Kinetic parameters of starch, soy protein and catechin during digestion in the SHIS}

The release of starch, soy protein isolate, and catechin as

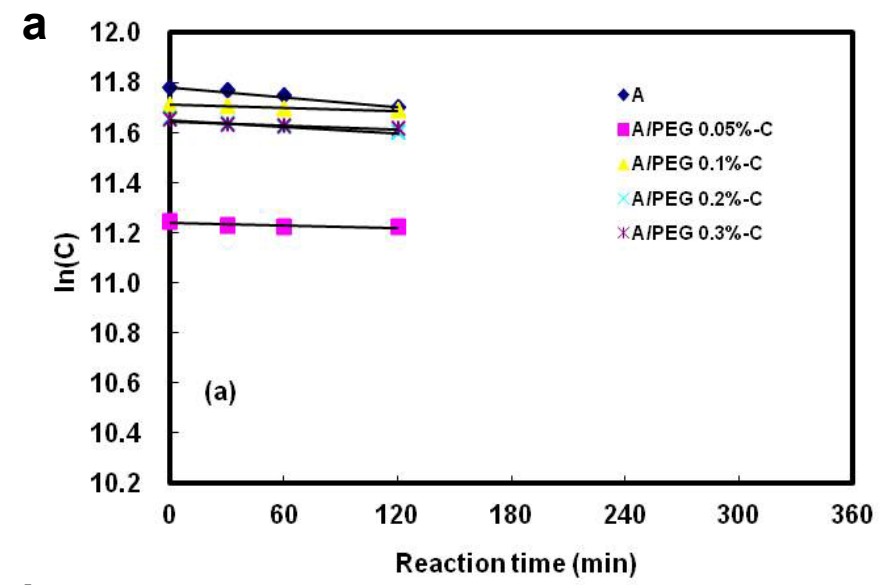

b

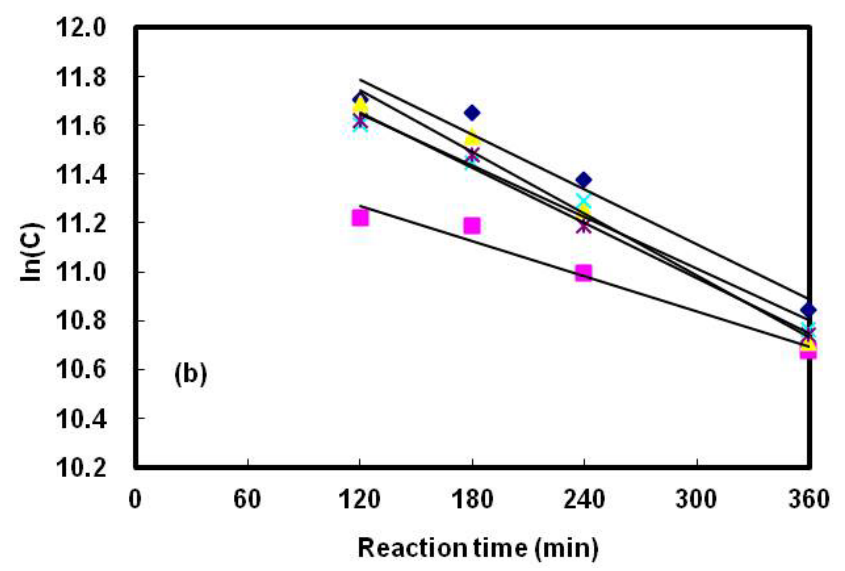

Figure 7. Effect of polyacryl emulsion coating on the digestion kinetics of alginate/PEG microcapsules in the simulated human intestinal system.

(a) Stomach vessel, (b) Small intestine vessel, A: 1.5\% alginate microcapsules, A/PEG $0.05 \%(0.1 \%, 0.2 \%, 0.3 \%)$-C: $1.5 \%$ alginate $/ 0.05 \%(0.1 \%, 0.2 \%, 0.3 \%)$ polyethylene glycolmicrocapsules coated with polyacryl emulsion.
Table 5. Yield and moisture contents of microcapsules with alginate and polyethylene glycol.

\begin{tabular}{|l|c|c|}
\hline Microcapsules & Efficiency yield (\%) & Moisture (\%) \\
\hline${ }^{*}$ A & $37.58 \pm 0.11^{\mathrm{D}}$ & $95.67 \pm 0.02^{\mathrm{A}}$ \\
\hline${ }^{\circ}$ A/PEG $0.05 \%$ & $44.16 \pm 0.05^{\mathrm{A}}$ & $95.31 \pm 0.06^{\mathrm{B}}$ \\
\hline A/PEG $0.1 \%$ & $44.06 \pm 0.02^{\mathrm{AB}}$ & $95.25 \pm 0.04^{\mathrm{B}}$ \\
\hline A/PEG $0.2 \%$ & $43.14 \pm 0.04^{\mathrm{C}}$ & $95.03 \pm 0.01^{\mathrm{D}}$ \\
\hline A/PEG $0.3 \%$ & $44.05 \pm 0.03^{\mathrm{B}}$ & $95.12 \pm 0.07^{\mathrm{C}}$ \\
\hline F-value & $6964.10^{* * *}$ & $89.59^{* * *}$ \\
\hline
\end{tabular}

"A: $1.5 \%$ alginate microcapsules

${ }^{\dagger} \mathrm{A} / \mathrm{PEG} 0.05 \%(0.1 \%, 0.2 \%, 0.3 \%): 1.5 \%$ alginate $/ 0.05 \%(0.1 \%, 0.2 \%, 0.3 \%)$ polyethylene glycol microcapsules

Mean in the same column with the different letters (A-D) are significantly different at $\mathrm{p}<0.05$ by Duncan's multiple test

Table 6. Yield and moisture contents of microcapsules with alginate, polyethylene glycol and polyacryl emulsion.

\begin{tabular}{|l|c|c|}
\hline Microcapsules & Efficiency yield (\%) & Moisture (\%) \\
\hline${ }^{*} \mathrm{~A}$ & $37.58 \pm 0.11^{\mathrm{D}}$ & $95.67 \pm 0.02^{\mathrm{A}}$ \\
\hline$\dagger \mathrm{\dagger} / \mathrm{PEG} 0.05 \%-\mathrm{C}$ & $37.55 \pm 0.04^{\mathrm{D}}$ & $94.55 \pm 0.03^{\mathrm{B}}$ \\
\hline A/PEG 0.1\%-C & $37.81 \pm 0.03^{\mathrm{C}}$ & $94.45 \pm 0.07^{\mathrm{C}}$ \\
\hline A/PEG 0.2\%-C & $38.34 \pm 0.03^{\mathrm{B}}$ & $94.48 \pm 0.02 \mathrm{~B}^{\mathrm{C}}$ \\
\hline A/PEG 0.3\%-C & $39.26 \pm 0.02^{\mathrm{A}}$ & $94.16 \pm 0.05^{\mathrm{D}}$ \\
\hline F-value & $503.77^{* * *}$ & $559.77^{* * *}$ \\
\hline
\end{tabular}

*A: $1.5 \%$ alginate microcapsules

${ }^{\dagger} \mathrm{A} / \mathrm{PEG} \quad 0.05 \% \quad(0.1 \%, \quad 0.2 \%, \quad 0.3 \%)$-C: $1.5 \%$ alginate $/ 0.05 \% \quad(0.1 \%, 0.2 \%, 0.3 \%)$ polyethylene glycol microcapsules coated with polyacryl emulsion

Mean in the same column with the different letters (A-D) are significantly different at $\mathrm{p}<0.05$ by Duncan's multiple test

Table 7. Kinetic parameters of starch, soy protein isolate and catechin during digestion in the simulated human intestinal system.

\begin{tabular}{|c|c|c|c|c|c|c|}
\hline & \multicolumn{3}{|c|}{ Stomach } & \multicolumn{3}{c|}{ Small intestine } \\
\hline & $\mathbf{r}^{\mathbf{2}}$ & $\begin{array}{c}\text { Rate } \\
\text { constant }\end{array}$ & $\begin{array}{c}\text { Half life } \\
\text { (min) }\end{array}$ & $\mathbf{r}^{\mathbf{2}}$ & $\begin{array}{c}\text { Rate } \\
\text { constant }\end{array}$ & $\begin{array}{c}\text { Half life } \\
\text { (min) }\end{array}$ \\
\hline Starch & 0.911 & 0.001 & 332376.7 & 0.915 & 0.002 & 3895.9 \\
\hline "SPI & 0.997 & 0.003 & 237.6 & 0.999 & 0.011 & 61.7 \\
\hline Catechin & 0.987 & 0.003 & 234.8 & 0.993 & 0.007 & 94.6 \\
\hline
\end{tabular}

"SPI: Soy protein isolate

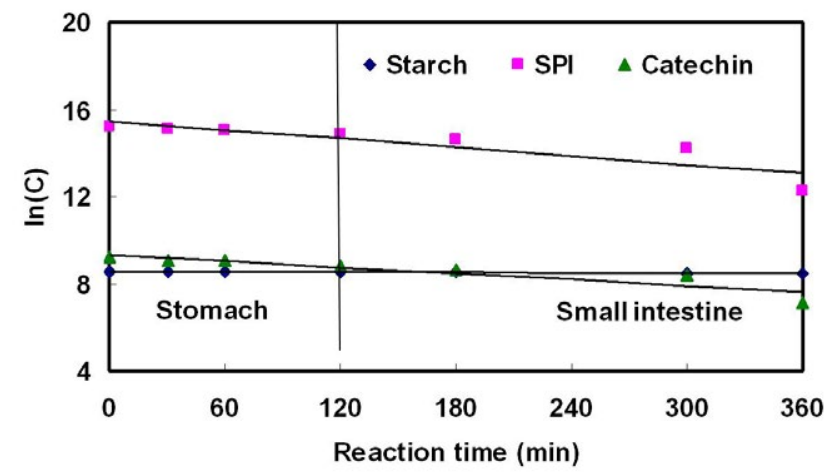

Figure 8. Kinetics of starch, soy protein isolate and catechin during digestion in the simulated human intestinal system. SPI: Soy protein isolate.

physiological material during SHIS reaction time is shown in Table 5 and Figure 8. Starch, soy protein isolate, and catechin were not completely digested in the stomach. However, the degree of digestion in the small intestine was increased in proportion to SHIS reaction 
time. Especially, the starch was hardly digested and remained almost unchanged. The half time of soy protein isolate and catechin was 237.6 and $234.8 \mathrm{~min}$ in the stomach phase and 61.7 and $94.6 \mathrm{~min}$ in the small intestine phase, respectively.

\section{Sponsoring agency} Korea.

This study was supported by the Korea Food Research Institute,

\section{References}

1. Marteau P, Minekus M, Havenaar R, Huis in’t Veld JH (1997) Survival of lactic acid bacteria in a dynamic model of the stomach and small intestine: validation and the effects of bile. J Dairy Sci 80: 1031-1037 [Crossref].

2. Blanquet S, Garrait G, Beyssac E, Perrier C, Denis S, et al. (2005) Effects of cryoprotectants on the viability and activity of freeze dried recombinant yeasts as novel oral drug delivery systems assessed by an artificial digestive system. Eur J Pharm Biopharm 61: 32-39 [Crossref].

3. Minekus M, Marteau P, Havenaar R, Huisin't Veld JHJ (1995) A multicompartmental dynamic computer controlled model simulating the stomach and small intestine. American Theol Libr Assoc 23: 197-209.

4. Yu LX, Crison JR, Amidon GL (1996) Compartmental transit and dispersion mode analysis of small intestinal transit flow in human. Int J Pharm 140: 111-118.

5. Larsson M, Minekus M, Havenaar R (1997) Estimation of the bioavailability of iron and phosphorus in cereals using a dynamic in vitro gastrointestinal model. J Sci Food Agr 74: 99-106.

6. Wong A, Toth I (2001) Lipid, sugar and liposaccharide based delivery systems. Curr Med Chem 8: 1123-1136 [Crossref].

7. Serp D, Cantana E, Heinzen C, Von Stockar U, Marison IW (2000) Characterization of an encapsulation device for the production of monodisperse alginate beads for cell immobilization. Biotechnol Bioeng 70: 41-53 [Crossref].

8. Ainsley Reid A, Vuillemard JC, Britten M, Arcand Y, Farnworth E, et al. (2005) Microentrapment of probiotic bacteria in a $\mathrm{Ca}(2+)$-induced whey protein gel and effects on their viability in a dynamic gastro-intestinal model. J Microencapsul 22: 603-619 [Crossref].

9. Zhu H, Srivastava R, McShane MJ (2005) Spontaneous loading of positively charged macromolecules into alginate-templated polyelectrolyte multilayer microcapsules. Biomacromolecules 6: 2221-2228 [Crossref].

10. Smrdel P, Bogataj M, Podlogar F, Planinsek O, Zajc N, et al. (2006) Characterization of calcium alginate beads containing structurally similar drugs. Drug Dev Ind Pharm 32: 623-633 [Crossref].

11. Huguet ML, Dellacherie E (1996) Calcium alginate beads coated with chitosan: effect of the structure of encapsulated materials on their release. Process Biochem 31: 745-751.

12. Qi L, Xu Z, Jiang X, Hu C, Zou X (2004) Preparation and antibacterial activity of chitosan nanoparticles. Carbohydr Res 339: 2693-2700 [Crossref].

13. Ribeiro AJ, Neufeld RJ, Arnaud P, Chaumeil JC (1999) Microencapsulation of lipophilic drugs in chitosan-coated alginate microspheres. Int J Pharm 187: 115-123 [Crossref].

14. Nan A, Ghandehari H (2005) Structure, properties, and characterization of polymeric biomaterials. In: R.I. Mahato, ed. Biomaterials for delivery and targeting of proteins and nucleic acids. Washington, D.C.: CRC Press: 2-36.

15. Aiedeh K, Gianasi E, Orienti I, Zecchi V (1997) Chitosan microcapsules as controlled release systems for insulin. J Microencapsul 14: 567-576 [Crossref].

16. Blanquet S, Zeijdner E, Beyssac E, Philippe M, Denis A, et al. (2004) A dynamic artificial gastrointestinal system for studying the behavior of orally administered drug dosage forms under various physiological conditions. Pharmaceut Res 21: 585-591.

17. Nurmi K, Ossipov V, Haukioja E, Pihlaja K (1996) Variation of total phenolic content and individual low-molecular-weight phenolics in foliage of mountain birch trees (Betula pubescens ssp.tortuosa). J Chem Ecol 22: 2023-2040 [Crossref].

18. Lowry OH, Rosebrough NJ, Farr AL, Randall RJ (1951) Protein measurement with the Folin phenol reagent. J Biol Chem 193: 265-275 [Crossref].

19. Wang SB, Chen AZ, Weng LJ, Chen MY, Xie XL (2004) Effect of drug-loading methods on drug load, encapsulation efficiency and release properties of alginate/ poly-L-arginine/chitosan ternary complex microcapsules. Macromol Biosci 4: 27-30 [Crossref].

20. Fujii T, Ogiwara D, Ohkawa K, Yamamoto H (2005) Alkaline phosphatase encapsulated in gellan-chitosan hybrid capsules. Macromol Biosci 5: 394-400 [Crossref].

21. Lim ST, Martin GP, Berry DJ, Brown MB (2000) Preparation and evaluation of the in vitro drug release properties and mucoadhesion of novel microspheres of hyaluronic acid and chitosan. J Control Release 66: 281-292 [Crossref].

22. Takayama K, Hirata M, Machida Y, Masada T, Sannan T, et al. (1990) Effect of interpolymer complex formation on bioadhesive property and drug release phenomenone of compressed tablet consisting of chitosan and sodium hyaluronate Chem Pharm Bull 38: 1993-1997.

23. Zhu H, Srivastava R, Brown JQ, McShane MJ (2005) Combined physical and chemical immobilization of glucose oxidase in alginate microspheres improves stability of encapsulation and activity. Bioconjug Chem 16: 1451-1458 [Crossref].

Copyright: (C2015 Choi AJ. This is an open-access article distributed under the terms of the Creative Commons Attribution License, which permits unrestricted use, distribution, and reproduction in any medium, provided the original author and source are credited. 